\title{
Article
}

\section{Interaction between Epsomite Crystals and Organic Additives}

Encarnacio\#n Ruiz-Agudo, Christine V. Putnis, and Carlos Rodriguez-Navarro Cryst. Growth Des., 2008, 8 (8), 2665-2673 • DOI: 10.1021/cg070442n • Publication Date (Web): 03 July 2008

Downloaded from http://pubs.acs.org on November 26, 2008
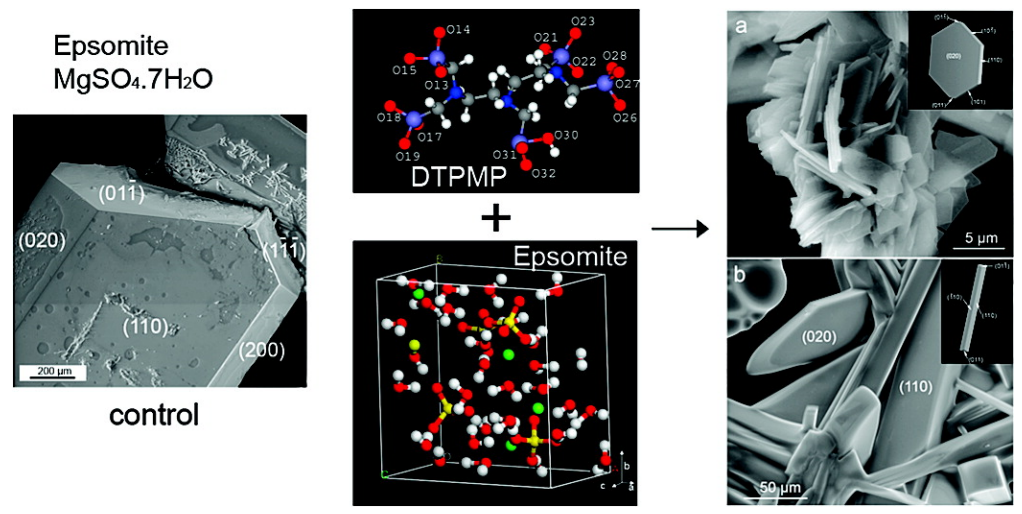

\section{More About This Article}

Additional resources and features associated with this article are available within the HTML version:

- Supporting Information

- Access to high resolution figures

- $\quad$ Links to articles and content related to this article

- Copyright permission to reproduce figures and/or text from this article

\section{View the Full Text HTML}

\section{ACS Publications}




\title{
Interaction between Epsomite Crystals and Organic Additives
}

\author{
Encarnación Ruiz-Agudo,$^{\dagger}$ Christine V. Putnis, ${ }^{\dagger}$ and Carlos Rodriguez-Navarro* ${ }^{*}{ }^{\dagger}$ \\ Departamento de Mineralogía y Petrología, Universidad de Granada, Fuentenueva s $/$, \\ 18002 Granada, Spain, and Institut für Mineralogie, Universität Münster, Correnststrasse 24, \\ 48149 Münster, Germany
}

\begin{abstract}
A number of phosphonates and carboxylates were tested as potential crystallization inhibitors for epsomite $\left(\mathrm{MgSO}_{4} \cdot 7 \mathrm{H}_{2} \mathrm{O}\right)$. Epsomite nucleation is strongly inhibited in the presence of amino tri(methylene phosphonic acid) (ATMP), diethylenetriaminepentakis (methylphosphonic acid) (DTPMP), and poly(acrylic acid) sodium salt (PA). These additives also act as habit modifiers promoting the growth of acicular crystals elongated along the [001] direction. Environmental scanning electron microscopy (ESEM), Fourier transform infrared spectroscopy (FTIR), atomic force microscopy (AFM), and molecular modeling of additive adsorption on specific epsomite $(h k l)$ faces are used to identify how these additives inhibit epsomite crystallization. Additives attach preferentially on epsomite $\{110\}$ faces, at edges of monolayer steps parallel to [001]. Step pinning and the eventual arrest of step propagation along $\langle 110\rangle$ directions account for the observed habit change. Hydrogen bonding between the functional groups of additive molecules and water molecules in epsomite $\{110\}$ appears to be the principal mechanism of additive-epsomite interaction, as shown by FTIR and molecular modeling. Molecular modeling also shows that DTPMP displays a high stereochemical matching with epsomite $\{110\}$ surfaces, which can explain why this is the most effective inhibitor tested. The use of such effective crystallization inhibitors may lead to more efficient preventive conservation of ornamental stone affected by epsomite crystallization damage.
\end{abstract}

\section{Introduction}

The term epsomite $\left(\mathrm{MgSO}_{4} \cdot 7 \mathrm{H}_{2} \mathrm{O}\right)$ was first used by de la Métherie in 1806 to refer to the "bitter salt" forming in the thermal springs of Epsom, Surrey (UK). However, earlier reports on the so-called "Epsom salt" exist. ${ }^{1}$ Epsomite is a widespread evaporite mineral ${ }^{2,3}$ and has played a number of roles of scientific interest over the last four centuries. ${ }^{1}$ It has numerous medical and pharmaceutical applications, for example, in the treatment of cardiac arrhythmia, acute asthma, eclampsia, and gallstones. ${ }^{4}$ It has been used in agriculture (fertilizer), cotton and silk manufacturing, ore processing, and as an additive in explosives. ${ }^{1,4}$ It is a raw material for manufacturing various chemicals containing magnesium and also has applications in the field of dosimetric measurements. ${ }^{5}$ Recently, epsomite has attracted a great deal of research interest because hydrated magnesium sulfates have been identified in meteorites, ${ }^{6,7}$ and their presence has been inferred on the surface of Mars ${ }^{9,10}$ and the Galilean satellites of Jupiter: Europa, Callisto, and Ganymede. ${ }^{11-14}$ Sulfates, and hydrated magnesium sulfates among them, represent ca. $30 \mathrm{wt} \%$ within saline sediments on Mars, and appear to account for equatorial hydrogen observed by Odyssey spacecraft. ${ }^{9}$ Hydrated magnesium sulfates thus seem to be significant contributors to the present day Martian watercycle, and may reveal much about the history of water on Mars. ${ }^{10}$ In addition, catastrophic dehydration of epsomite-rich formations has been claimed to account for the development of outflow channels on Mars. ${ }^{15,16}$ Evidence of saline water oceans beneath the ice crusts of Europa, Callisto, and Ganymede has bolstered speculation that they may harbor life. ${ }^{11,13}$ The study of the formation and transformations of magnesium sulfate salts in pure inorganic or organic-rich systems may therefore have profound implications for the understanding of current conditions which may support life on Mars or on the Galilean satellites of Jupiter.

* To whom correspondence should be addressed. E-mail: carlosrn@ugr.es tel: +34 958 246616; fax: +34958 243368 .

Universidad de Granada.

* Universität Münster.
Epsomite is also a common salt that contributes to the weathering of a range of rocks and building materials all over the world. ${ }^{17-19}$ Its weathering influence has made this sulfate one of the chosen salts with which to perform standard accelerated decay tests for building materials. ${ }^{20}$ Crystallization pressure exerted by epsomite crystals when grown in a confined space can lead to significant damage to porous ornamental stone ${ }^{21}$ typically resulting in the disintegration and loss of priceless pieces of architectural and sculptural heritage. ${ }^{22}$ Sulfates, that are mainly derived from groundwater, ${ }^{19}$ seawater, ${ }^{23}$ and/or atmospheric pollution, ${ }^{24}$ in combination with $\mathrm{Mg}$-rich building materials such as dolostones and/or dolomitic lime mortars, are related to stone decay by epsomite. ${ }^{17,25-27}$

There are a number of conservation treatments for porous ornamental stone affected by salt weathering. ${ }^{28,29}$ However, such treatments (e.g., application of organic consolidants such as acrylic resins) tend to mask the effects of salt weathering and do not tackle the problem before it starts (i.e., they are not preventive treatments). ${ }^{29}$ Recently, it has been proposed that additives that modify salt crystallization processes could be a new means to halt and/or mitigate salt weathering affecting sculptural and architectural stone. ${ }^{29-32}$ Additives dosed at low concentrations (ppm) either inhibit or promote salt crystallization. In the first case, they favor the formation of harmless salt efflorescence on stone surfaces, being effective in desalination treatments. ${ }^{32}$ Because of the eventual loss of additive incorporated into efflorescence crystals, maintenance (i.e., repeated application of the treatment over time) might be necessary. In the second case, that is, promotion, salt crystallization occurs in the stone pores at a relatively low supersaturation, resulting in low crystallization pressure and minimal damage. ${ }^{29}$ Ferrocyanides have been shown to be effective in minimizing salt damage due to $\mathrm{NaCl}$ crystallization in porous stone, mortars, and bricks due to their high crystallization inhibition capacity and their ability to promote efflorescence growth. ${ }^{32,33}$ Some phosphonates inhibit the crystallization of mirabilite $\left(\mathrm{NaSO}_{4} \cdot\right.$ $10 \mathrm{H}_{2} \mathrm{O}$ ), thus representing a potential treatment for materials affected by this damaging salt. ${ }^{29}$ However, little is known about 
the effects of phosphonates, as well as other organic additives, on the crystallization of other damaging soluble salts such as epsomite. Furthermore, despite the widespread use of phosphonates, carboxylates, and polyacrylates, among other common additives, in preventing/delaying the crystallization of sparingly soluble salts, such as barite,${ }^{34-40}$ calcite, ${ }^{41-44}$ pyrite, ${ }^{45}$ calcium oxalate, ${ }^{46,47}$ and hydroxyapatite, ${ }^{48,49}$ their action on nucleation and crystal growth is however not yet fully understood. ${ }^{4}$ On the other hand, although much research has been dedicated to the study of the interaction between sparingly soluble alkali earth salts and organic additives, very little is known about the interaction of organic additives with divalent cations in highly soluble salts such as magnesium sulfates. To our knowledge only two papers studied the effects of organics, a surfactant (sodium dodecyl sulfate) ${ }^{50}$ and urea, ${ }^{5}$ on the crystallization of epsomite.

It is the aim of this work to evaluate the effects of several organic additives dosed at different concentrations and $\mathrm{pHs}$ on the crystallization of epsomite as a first step to indicate if they can be effective as a conservation treatment for salt damaged ornamental stone. The additives tested include (a) poly(carboxylic) acids and derivatives (citric acid, CA; aspartic acid sodium salt, AAS; poly(acrylic acid, sodium salt), PA, with molecular weight of 2100), and (b) poly(phosphonic) acids such as 1-hydroxyethylidene-1,1-diphosphonic acid (HEDP), amino tri(methylene phosphonic acid) (ATMP), and diethylenetriaminepentakis (methylphosphonic acid) (DTPMP). All of these additives are commonly used as crystallization inhibitors in industrial and technical applications. The role of chemical and structural factors (i.e., matching between additive functional groups and specific crystal faces of the growing salt) on the effects of the additives in epsomite crystallization have been investigated at different length-scales (from the molecular scale to the microscale) combining scanning electron microscopy, atomic force microscopy, infrared spectroscopy, and molecular modeling.

\section{Methodology}

2.1. Batch Crystallization Tests. Batch crystallization tests were carried out using a special laboratory set up designed to allow crystallization of salt solutions following free evaporation in a controlled environmental chamber $\left(T=25 \pm 2{ }^{\circ} \mathrm{C} ; \mathrm{RH}=40 \pm 10 \%\right)$. Details of the experimental setup have been previously published. ${ }^{32}$

A stock saturated magnesium sulfate solution was prepared using anhydrous solid (Panreac, analytical grade) and deionized water. The saturated solution was decanted to remove any undissolved solid. Additives were dosed to the saline solution in concentrations ranging from $10^{-4}$ to $10^{-1} \mathrm{M}$. Additives acidify the saturated magnesium sulfate solution (from $\mathrm{pH} \sim 7$ down to $\mathrm{pH} 3.2-4.0$ ); thus, the $\mathrm{pH}$ was adjusted to the target $\mathrm{pH}$ with $\mathrm{NaOH}$. Evaporation rate and supersaturation were assessed from measurements of weight loss following free evaporation of the saline solution and conductivity (Orion $\mathrm{pH}$-conductivity unit). Both measurements were performed continuously to determine induction time, that is, elapsed time between the beginning of the test and the onset of crystallization, and critical supersaturation, that is, supersaturation reached at the onset of crystallization, which was calculated using the formula $\sigma=100\left(C-C_{0}\right) / C_{0}$, with $C$ and $C_{0}$ being the actual and the saturation concentrations, respectively. In a few cases, the onset of crystallization was assessed by a sudden change in the slope of the conductivity vs time curve, ${ }^{51}$ corresponding to the visual detection of precipitates. However, in most cases, conductivity measurements were not valid to determine the onset of crystallization. In these latter cases, conductivity variations either showed no clear trend, or a constant conductivity reduction was observed right from the start of the run, with no change in the slope of the conductivity vs time curve after precipitates were visually observed. Thus, the crystallization onset was detected visually. Since growth inhibition (G.I.) values were used for comparison purposes, eventual (systematic) errors associated with visual detection of crystallization onset should not affect the interpretation of the results. ${ }^{29}$

2.2. Analysis of Precipitates. Following crystallization, precipitates were collected and observed by means of optical microscopy and environmental scanning electron microscopy (ESEM, FMI Quanta 400). No sample preparation was required before ESEM observations. Additionally, the crystallization of epsomite in a saturated magnesium sulfate solution drop (with and without additives) was observed in situ, at high magnification, within the ESEM chamber. Crystallization was achieved by reducing the water pressure in the chamber (from 6.5 to 2.5 Torr) at $5{ }^{\circ} \mathrm{C}$. The temperature of the sample-holder was controlled with a Peltier stage. Digital photomicrographs were recorded during the crystallization event. Details on the use of the ESEM for dynamic crystallization experiments have been reported elsewhere. ${ }^{52}$ Powder $\mathrm{X}$-ray diffraction (XRD) patterns of the precipitates were obtained on a Phillips PW 1547 diffractometer with $\mathrm{Cu} \mathrm{K} \alpha$ radiation $(\lambda=1.5418$ $\AA$ ). The vibrational spectral characteristics of magnesium sulfate crystals were studied on a Nicolet IR200 Fourier transform infrared spectrometer (FTIR) using the $\mathrm{KBr}$ pellet method.

Atomic force microscopy (AFM) was used to study the surface topography of epsomite crystals grown with and without additives. Observations of epsomite growth surfaces were conducted at $25{ }^{\circ} \mathrm{C}$ using a Multimode Nanoscope III (Digital Instruments) working in contact mode. All images were taken using high aspect ratio $\mathrm{Si}_{3} \mathrm{~N}_{4}$ tips with a typical radius of curvature of $\sim 10 \mathrm{~nm}$. The images were reproducible with different tips and with different sample positions and orientations. The growth surfaces studied were $\{110\}$ faces of optically clear epsomite single crystals, grown with and without additives. Such surfaces are the most important in epsomite (see below). Only images collected at different scan angles and displaying the same morphological features were recorded and used for further analysis.

2.3. Molecular Modeling of Epsomite Morphology and Additive-Epsomite Interactions. The MSI Cerius ${ }^{2}$ computer program (Accelerys, San Diego) was used to model epsomite morphology using three different methods for predicting the external morphology of crystalline materials: (a) the Bravais, Friedel, Donnay and Harker (BFDH) algorithm, which is an approximation based on a geometrical calculation that uses the crystal symmetry and lattice parameters to generate a list of possible growth faces and their relative growth rates from which crystal morphology can be deduced, without considering the cell formulation or using energy parameters. Assuming that growth involves consecutively adding growth planes of atoms and molecules, and if energetic effects are not taken into account, the ease of adding a plane is proportional to its thickness. Thus, a thicker growth plane grows more slowly and has a smaller center-to-face distance, and as a consequence, it would be most likely to appear in the crystal; (b) the attachment energy (AE) method, which relies on a calculation of the energy released when a growth slice is added to a growing plane for predicting the growth morphology of a crystal. It can predict the shape of a crystal more accurately than the BFDH method because it takes the energetics of the system into account, although this is not always the case (see following section). The growth rate of the crystal face is proportional to its AE. That is, faces with the lowest attachment energies are the slowest growing and, therefore, have the most morphological importance. The AE is calculated for a series of suitable $(h k l)$ slices that are chosen by performing a Donnay-Harker prediction. From the energy calculation and, hence, the growth rate, a center-toface distance is assigned to each face. Both BFDH and AE predict the relative growth rates of possible growth faces; (c) in contrast, the surface energy (SE) method predicts the equilibrium morphology which minimizes the total surface energy of the crystal (Gibbs-Wulff model) by determining the surface energy of the relevant faces. The equilibrium morphology is calculated at zero temperature. The calculated surface energy is an average between the surfaces with Miller indices $\{h k l\}$ and $\{-h-k-l\}$. The latter restriction is important for noncentrosymmetric crystals (i.e., epsomite, with space group $\left.P 22_{1} 2_{1} 2_{1}\right){ }^{53}$ Both AE and SE methods assume that the surface is a perfect termination of the bulk and that no surface relaxation takes place.

Morphology calculations (BFDH, AE, and SE) were performed in order to identify the key growth faces of epsomite, that is, those faces that are morphologically more important because they display slower growth rates, and therefore would be most probable candidates for additive adsorption. Several surface cells were created from the epsomite 
unit cell at a given Miller plane (cleavage plane) corresponding to the dominant growth faces. These surface cells were further extended to a block of three or nine cells. On these cells, possible docking positions of the additive molecules were tested superimposing each of the molecules on these faces. Prior to this, the structure of the most effective additive (in terms of crystallization inhibition, i.e., DTPMP: see below) was optimized following the methodology outlined by Ruiz-Agudo et al. ${ }^{29}$ This approach gave a crude, yet effective approximation as to whether the phosphonic acid groups in the additive would be capable of binding to at least two $\mathrm{Mg}$ ions in the epsomite lattice. A similar approach has been used successfully by Cody and Cody,${ }^{46}$ Bosbach et al., ${ }^{38}$ and Ruiz-Agudo et al. ${ }^{29}$ It has been shown that for effective interaction between additive and crystals, the molecule of the additive has to have several functional groups. ${ }^{54}$ Note also that additives that bind simultaneously at two surface sites will be much more effective at blocking step growth than a single ion molecule. ${ }^{36}$ At least two functional groups were thus required for modeling phosphonate adsorption onto epsomite (bidentate adsorption) as in Pina et al. ${ }^{40}$ and Ruiz-Agudo et al. ${ }^{29}$

\section{Results and Discussion}

3.1. Critical Supersaturation and Induction Time: Effect of Additive Concentration and pH. In order to compare the effects of the different additives tested, critical supersaturation data were normalized with respect to the control critical supersaturation by using percentage of growth inhibition (G.I.). ${ }^{55}$ The latter is calculated using the formula:

$$
\text { G.I. }=\frac{\sigma_{\text {additive }}-\sigma_{\text {blank }}}{\sigma_{\text {blank }}} \times 100
$$

where $\sigma_{\text {additive }}$ and $\sigma_{\text {blank }}$ are the critical relative supersaturation in the presence and in the absence of the additive, respectively. In the absence of additives, the critical relative supersaturation $\sigma_{\text {blank }}$ was found to be $42.9 \pm 4.2 \%$. Critical supersaturation reached in the presence of additives can be calculated by substituting such a value in eq 1 . Additives did not affect significantly evaporation rates, and thus changes in critical supersaturation were attributed to inhibiting or promoting effects of these compounds on epsomite crystallization. In all cases, growth inhibition increased with additive concentration (Figure 1a). This can be due to a higher percentage of surface coverage by the additive as concentration increases. Regarding the effect of $\mathrm{pH}$, its rise resulted in increased inhibition capacity of additives on magnesium sulfate precipitation up to $\mathrm{pH} \sim 8$. Note however that upon further $\mathrm{pH}$ increase the degree of inhibition was reduced (Figure 1b). It is worth mentioning the huge growth inhibition capability ( $210 \%)$ displayed by DTPMP when dosed at a high concentration ( $0.1 \mathrm{M}$; pH 8$)$. ATMP, HEDP, and PA also show a high inhibition capability at these same conditions (G.I. 90-130\%). Citric acid displayed a moderate effectiveness as a magnesium sulfate crystallization inhibitor (G.I. $\sim 70 \%$ ). Aspartic acid sodium salt had no detectable effect on magnesium sulfate crystallization under our experimental conditions. These results show that both the phosphonates and the polyacrylates tested are very effective nucleation inhibitors. Note, however, that at the lowest concentration tested, these additives act as nucleation promoters (Figure 1a). This can be explained considering that at a low additive concentration, additive molecules adsorbed onto the surface of the glass crystallization dish may deplete the effective additive bulk concentration in solution. Such adsorbed additive molecules will therefore not interact with magnesium sulfate clusters (with a size below the critical size) in the bulk solution and, thus, will not contribute to nucleation inhibition. On the other hand, additive molecules adsorbed on the walls of the crystallization dish may act as a template for heterogeneous nucleation of magnesium sulfate at
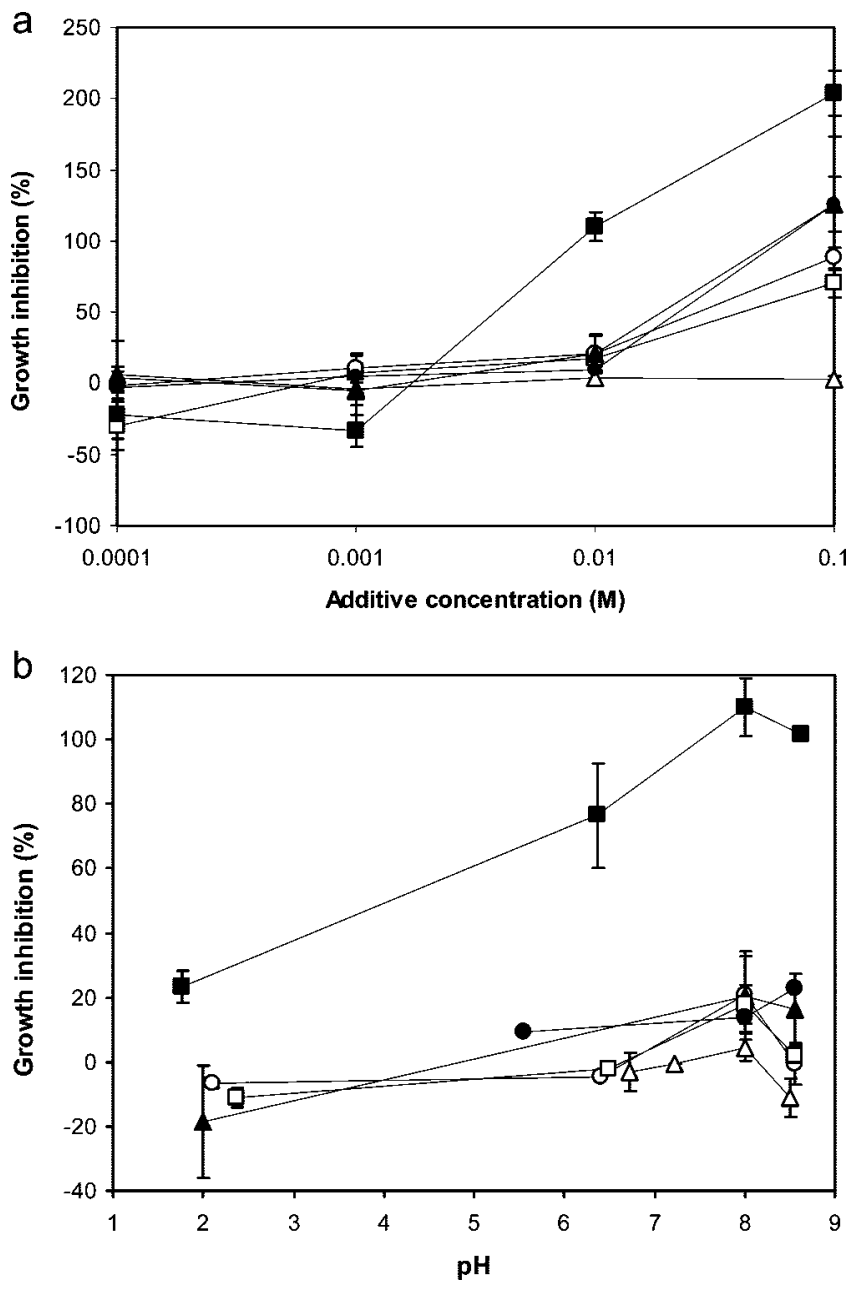

Figure 1. (a) Percentage of growth inhibition (G.I.) vs inhibitor concentration (at $\mathrm{pH} \sim 8$ ) for saturated magnesium sulfate solutions; and (b) percentage of G.I. vs $\mathrm{pH}(0.01 \mathrm{M}$ additive concentration)) for saturated magnesium sulfate solutions: (O) ATMP, (ム) HEDP, (ם) DTPMP, $(\square) \mathrm{CA},(\Delta) \mathrm{AAS}$, and $(\bullet)$ PA.

a low supersaturation. A similar effect has been described in the case of mirabilite ${ }^{29}$ and hydroxyapatite. ${ }^{49}$ At higher additive concentration, there are enough additive molecules in solution to be able to adsorb onto the surface of magnesium sulfate clusters with a size below the critical size, thus inhibiting magnesium sulfate nucleation and increasing G.I. values. In the case of the phosphonates, formation of Mg-phosphonate complexes ${ }^{56}$ could also contribute to the high G.I. values observed at high additive concentrations.

Figure 2 shows the distribution of ionic species for AAS, $\mathrm{CA}$, and PA, calculated from published $\mathrm{p} K_{\mathrm{a}}$ values. ${ }^{57,58}$ Distribution of phosphonate species with $\mathrm{pH}$ can be found in a report by Ruiz-Agudo et al. ${ }^{29}$ In all cases, functional groups in inhibitor molecules are highly deprotonated at $\mathrm{pH} 8-8.5$, which is when the additives display their maximum inhibitory capacity. Higher $\mathrm{pH}$ values do not lead to a significant change in the distribution of ionic species. Hence, it is unlikely that a change in the inhibition capacity at these moderately alkaline $\mathrm{pH}$ values is related to the protonation state of the additive. Therefore, it should be considered that the salt crystal surface becomes increasingly negative and may thus electrostatically repel the ionized inhibitor molecules as $\mathrm{pH}$ rises. It has been claimed that the latter effect accounts for the reduction in nucleation inhibition at high $\mathrm{pH}$ in the case of $\mathrm{BaSO}_{4}{ }^{39}$ and $\mathrm{Na}_{2} \mathrm{SO}_{4} \cdot$ 


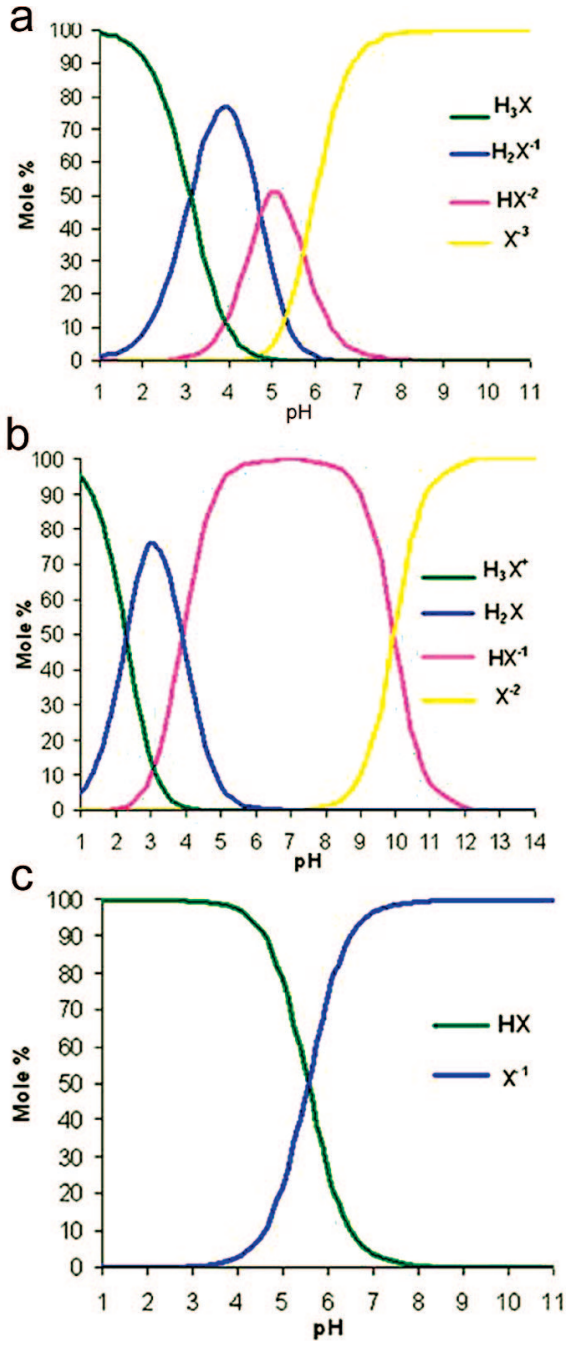

Figure 2. Distribution of ionic species as a function of $\mathrm{pH}$ : (a) $\mathrm{CA}$; (b) AAS; and (c) PA.

$10 \mathrm{H}_{2} \mathrm{O} .{ }^{29}$ Another possibility is that the crystal surface loses hydration water protons, therefore limiting its capacity to establish hydrogen bonds with the inhibitor molecule. ${ }^{39}$ Both latter effects may act simultaneously here.

3.2. Phases and Morphology. Epsomite was the only phase formed in the control solution and was identified by X-ray diffraction (XRD). This is in agreement with Hogenboom et al. ${ }^{59}$ who stated that at room temperature (and below $48{ }^{\circ} \mathrm{C}$ ) epsomite is the stable magnesium sulfate in equilibrium with a saturated solution. No Mg-additive phases (e.g., Mg-phosphonates) were detected. Figure $3 a, b$ shows epsomite crystals formed in the additive-free (control) run, with $\{110\}$ as the dominant form. This form is reportedly the most important in epsomite crystals formed in near-equilibrium conditions. ${ }^{53}$ Changes in epsomite morphology were observed following addition of HEDP, ATMP, DTPMP, and PA to the saturated salt solution (Figure 3). Such changes were most significant when additives were dosed at the highest concentration of 0.1 M. In the presence of ATMP, DTPMP, and PA, epsomite crystals changed from prismatic or blocky to acicular or needleshaped (Figure $3 d-f$ ). Habit changes were not so drastic in the case of HEDP (Figure 3c). This can be either due to structural mismatching between HEDP molecules and epsomite $\{110\}$ faces, or to the lower number of phosphonate groups in HEDP compared to the other phosphonates. The latter explanation is however not consistent with the relatively high growth inhibition values reached in the presence of HEDP (see subsection 3.1.). Citric acid and aspartic acid sodium salt had no detectable influence on the growth morphology of epsomite crystals. In a few cases, plate-like crystals with overdeveloped $\{020\}$ faces were formed in the presence of DTPMP and PA (Figure 4). The significant changes in morphology observed in the case of DTPMP and PA, and (to a lesser extent) ATMP, suggest that a strong interaction between epsomite crystals and these additives took place. On the other hand, formation of crystal aggregates in the presence of the latter additives points to a high nucleation density taking place at a high supersaturation, ${ }^{60}$ which is in agreement with measured G.I. values (Figure 1).

The mechanism of crystal-additive interactions can be inferred by observing changes in growth morphology, as described by Sikiric et al. ${ }^{54}$ The authors state that the morphology of a growing crystal is determined by the relative growth rates of its faces. The faster the growth rate in the direction perpendicular to a particular face, the smaller that face forms. Taking this into account, the above-described habit changes could be interpreted through preferential additive adsorption on (or incorporation into) epsomite $\{110\}$ faces and, to a lesser extent, on $\{020\}$ faces. The growth of these faces is thus slowed down, resulting in the overdevelopment of the $\{110\}$ form along the $c$-axis that changes the crystals' habit from blocky or prismatic to acicular (Figures 3 and 4), or in the formation of tabular $\{020\}$ forms (Figure 4). Habit changes resulting in the overdevelopment of $\{110\}$ forms have been observed in the case of epsomite crystals grown in the presence of sodium dodecyl sulfate ${ }^{50}$ and urea. ${ }^{5}$ Overall, these observations suggest that the interaction of organic additives and epsomite crystals follows a general mechanism that is not highly dependent on the additive structure. Such a mechanism could be related to hydrogen bonding between additive functional groups and epsomite water molecules, as suggested by Ruiz-Agudo et al. ${ }^{4}$

3.3. FTIR Analysis. The FTIR spectrum of magnesium sulfate is shown in Figure 5. The sulfate anion presents four normal modes in the infrared region: a nondegenerate symmetric stretch $v_{1}$, a doubly degenerate symmetric bending $v_{2}$, and two (triply degenerate) asymmetric stretching and bending, $v_{3}$ and $v_{4}$, respectively. ${ }^{61}$ Changes in solvation, metal complexation and protonation of $\mathrm{SO}_{4}{ }^{2-}$ can modify $\mathrm{S}-\mathrm{O}$ bond length and, as a result, may change the symmetry of the anion. This leads to a shift in the vibrational bands to different wavenumbers and causes the degenerate vibrations to become nondegenerate. The symmetric stretch does not show significant trends with the type of cation bonded to the anion. The weak sharp band at 945 $\mathrm{cm}^{-1}$ belongs to the symmetric $\mathrm{SO}_{4}$ stretch $\left(v_{1}\right)$ and indicates that the oxygens of the anion are not in symmetrically equivalent environments. ${ }^{62}$ The asymmetric sulfate stretch $v_{3}$ appears at $1095 \mathrm{~cm}^{-1}$. The bending mode of sulfate $\left(v_{4}\right)$ is positioned at around $615 \mathrm{~cm}^{-1}$. The broad envelope around $3400 \mathrm{~cm}^{-1}$ indicates the presence of water and it belongs to free water symmetric stretch. The asymmetric stretch of water is observed at $1660 \mathrm{~cm}^{-1}$. The hydrogen bonded $\mathrm{O}-\mathrm{H}$ stretching frequency is observed in the region between 2000 and $3200 \mathrm{~cm}^{-1}{ }^{63}$ The corresponding water bending mode is observed at around 420 $\mathrm{cm}^{-1}$. The FTIR spectrum of DTPMP doped crystals shows important modifications compared with that of the control (Figure 5). C-H stretching bands are observed at 2925 and 2855 $\mathrm{cm}^{-1}$ and the corresponding bending bands are observed at 1460 and $1380 \mathrm{~cm}^{-1}$. The broad band at ca. $2300 \mathrm{~cm}^{-1}$, hydrogen bonded $\mathrm{OH}$ stretch, in the spectrum of pure magnesium sulfate appeared more broadened and less well defined in the case of 

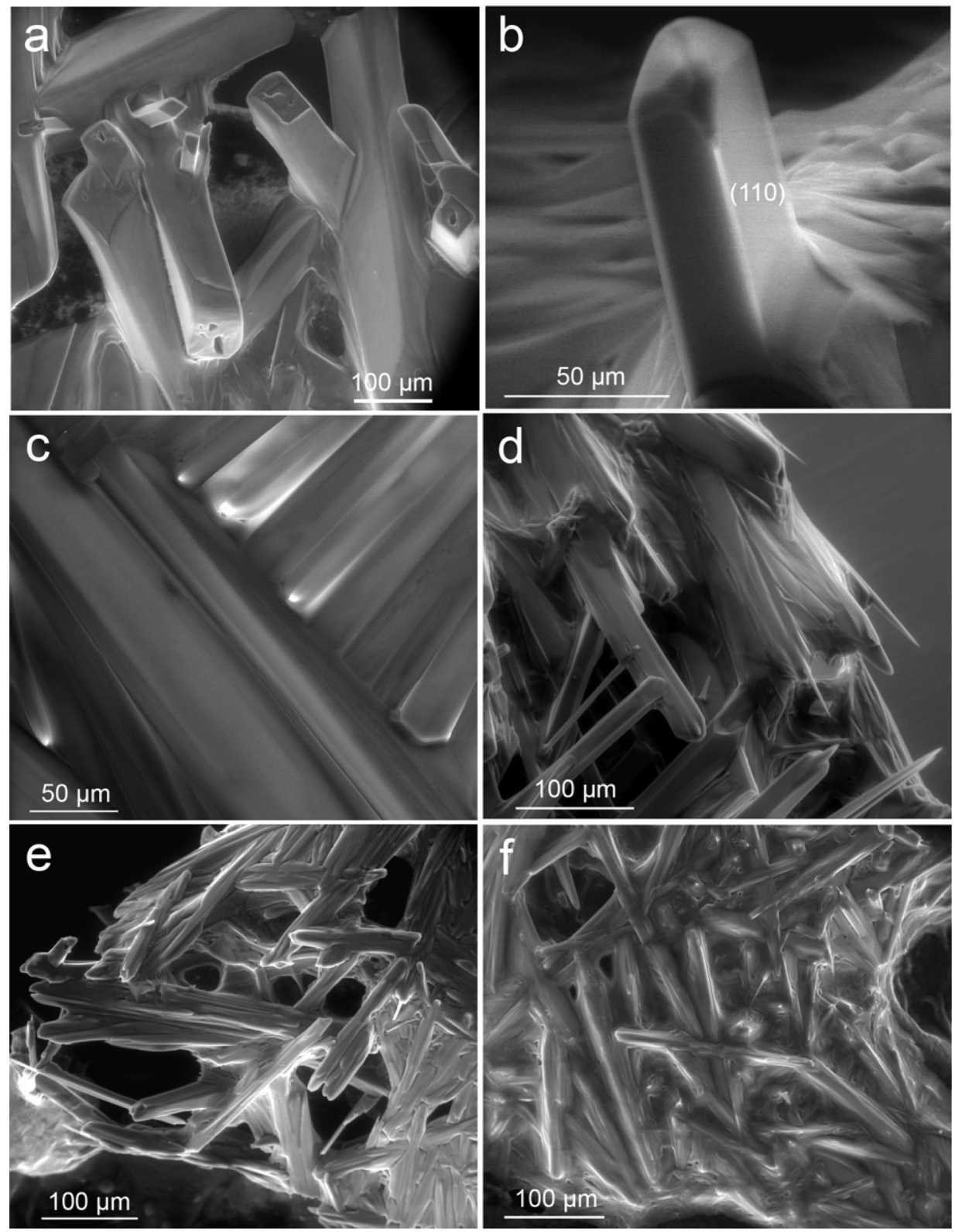

Figure 3. ESEM photomicrographs of epsomite crystals formed in (a and b) pure solution, and in the presence of (c) HEDP, (d) ATMP, (e) DTPMP, and (f) PA dosed at a concentration of $0.01 \mathrm{M}$.

DTPMP-doped magnesium sulfate. This can be due to hydrogen bonding between the additive and the hydration water. Hydrogen bonding has a significant influence on this peak shape and intensity, causing mainly a peak broadening. ${ }^{64}$ This is also observed in the case of PA-doped crystals (Figure 5). In this latter case, additional $\mathrm{C}=\mathrm{O}$ bands appear at 1662, 1564, and $1419 \mathrm{~cm}^{-1}$. FTIR analyses point out the presence of both DTPMP and PA in the magnesium sulfate lattice. Regarding the rest of the additives tested, a broadening in the $2300 \mathrm{~cm}^{-1}$ band was observed in the case of HEDP- and ATMP-doped crystals (Figure 5), while no differences in FTIR spectra (if compared with the control) were observed in the case of CAand AAS-doped crystals. Ruiz-Agudo et al. ${ }^{4}$ kinetic analysis of the thermal dehydration of epsomite gives evidence that higher activation energies are required to dehydrate DTPMPand PA-doped epsomite crystals if compared with the additivefree control. The authors suggested, in agreement with the results here presented, that hydrogen bonding between the additives and epsomite hydration water might explain such an increase in activation energy. Both the results presented by Ruiz-Agudo et al. $^{4}$ and those presented here point to a strong molecular interaction of phosphonates (DTPMP in particular) and the polyacrylate (PA) with the epsomite structure.

3.4. AFM Observations of Epsomite Growth Surfaces. Growth of epsomite crystals in additive-free solution occurs along flat steps parallel to the [001] direction. Next to the edge of the crystal, steps parallel to [11̄2] appear. Typically, growth steps spread from screw dislocations. The overall growth mechanisms thus follows a Burton-Cabrera-Frank crystal growth model, that is, growth at relatively low supersaturation. ${ }^{60}$ Figure 6a shows two arrays of growth steps parallel to [001] and [11̄2], respectively. Steps parallel to [001] are about $4 \AA$ high, a value that corresponds to half-d $\mathrm{d}_{110}$-spacing $(8.44 \AA$ ), while steps parallel to [11 2 ] are $\sim 8 \AA$ high (i.e., one $\mathrm{d}_{110^{-}}$ spacing). In the former case, steps are monomolecular, while in the latter case, two molecular layers exist related by a $2_{1}$ screw axis symmetry operation. The additives most effective as nucleation inhibitors and habit modifiers, that is, ATMP, 

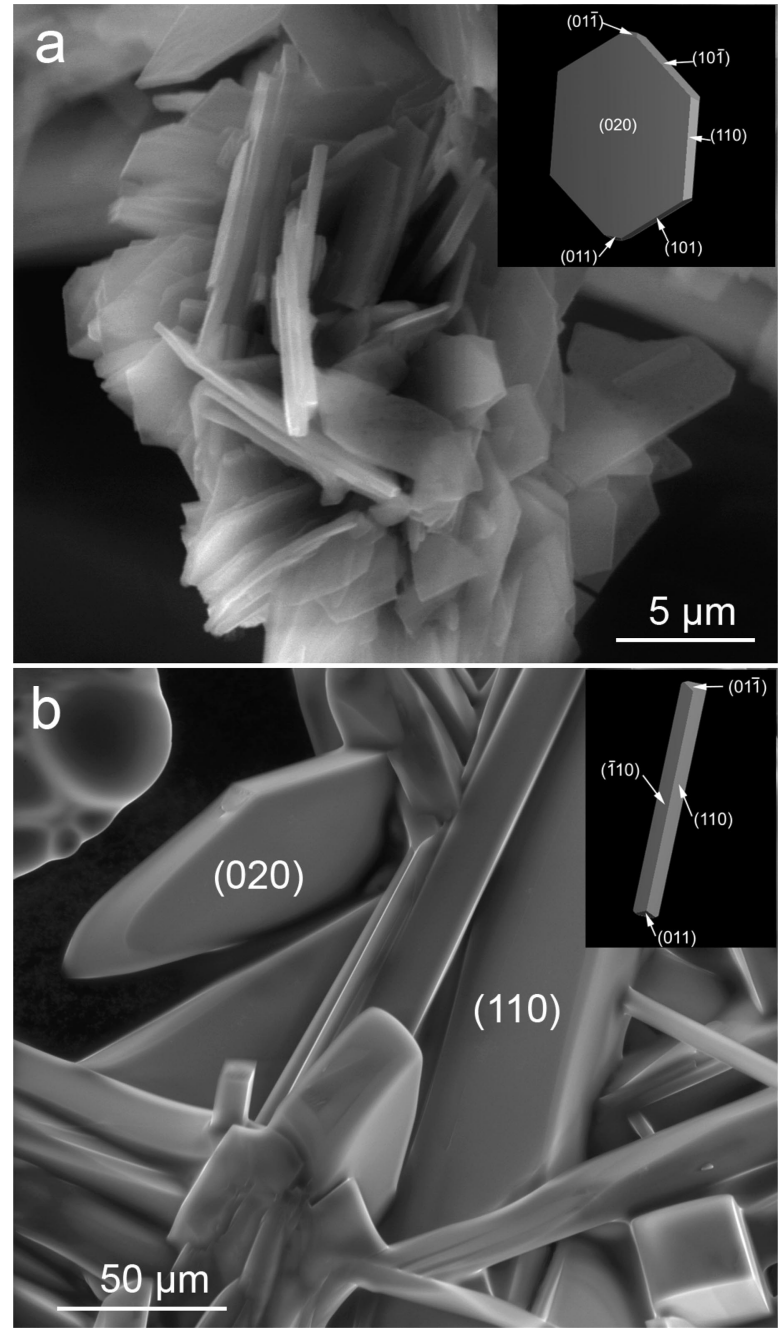

Figure 4. Detailed ESEM photomicrographs of epsomite crystals showing overdevelopment of $\{110\}$ and $\{010\}$ forms when grown in the presence of $0.01 \mathrm{M}$ DTPMP (a) and $0.01 \mathrm{M}$ PA (b). Insets show a schematic of overdeveloped $\{110\}$ and $\{010\}$ forms (images generated using Cerius $^{2}$ computer code).

DTPMP, and PA, display a clear effect on epsomite growth at the molecular scale. In the presence of PA and DTPMP the $\{110\}$ faces of epsomite crystals appeared rougher (Figure $6 b-d)$. Figure $6 b$ shows scalloped steps developed in the presence of DTPMP. Figure $6 \mathrm{c}$ shows some nuclei on $\{110\}$ surfaces grown in the presence of PA. These nuclei are about $40-50 \mathrm{~nm}$ high. They most probably formed due to twodimensional nucleation at the surface and displayed morphologies typical of a birth-and-spread growth mechanism. ${ }^{65}$ Additive ions occupying growth sites disrupt growth leading to the formation of protuberances (nuclei) on the surface. ${ }^{66,67}$ These observations point to growth at a high supersaturation, in agreement with G.I. results. Note also that step propagation along $\langle 110\rangle$ is hampered, resulting in accumulation of steep step edges along [001] (Figure 6d). This occurs following additive molecule adsorption at step edges. The inhibition of step propagation along $\langle 110\rangle$ explains the needle-like morphology of epsomite crystals, elongated along the [001] direction, observed with the ESEM. The $\{110\}$ faces of epsomite crystals grown in the presence of ATMP show scalloped steps (Figure $6 \mathrm{e})$. This is due to step pinning which occurs when inhibitor molecules adsorb at step edges interfering with their advancement and reducing step edge free energy. ${ }^{37}$ Molecules adsorbed

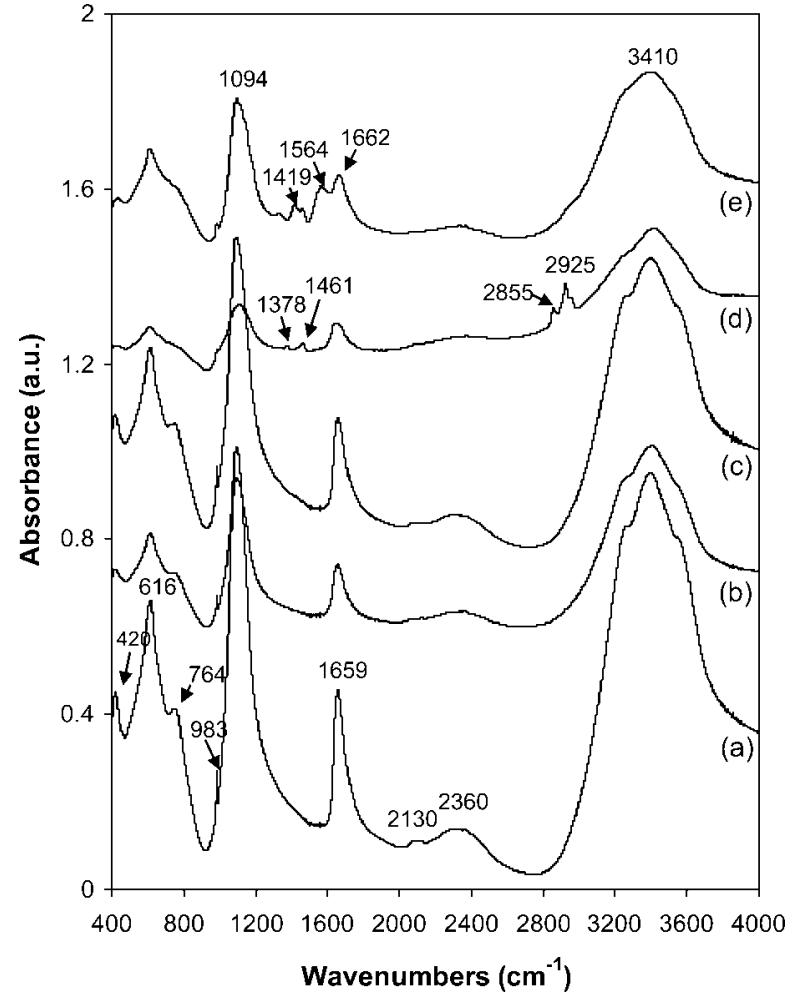

Figure 5. FTIR spectra of epsomite crystals formed in (a) saturated; (b) 0.01 M HEDP; (c) $0.01 \mathrm{M}$ ATMP; (d) $0.01 \mathrm{M}$ DTPMP; and (e) 0.01 M PA magnesium sulfate solutions.

on the surface make the addition of growth units discontinuous. ${ }^{67}$ Formation of a layer of soft material onto the $\{110\}$ surface of epsomite was observed in the case of crystals formed in the presence of ATMP and HEDP (Figure 6f). Such surfaces seem to be covered by an organic coating that it is easily removed by the AFM tip. A similar effect was observed by Pina et al. ${ }^{40}$ in the case of Barite grown in the presence of a high concentration of phosphonates. In the case of CA- and AASdoped epsomite crystals, limited secondary nucleation on (110) faces was observed (Figure 6g,h). However, no step pinning was detected. These observations are consistent with the limited growth inhibition effect of these two latter additives.

These results are consistent with a mechanism of crystal-additive interaction through adsorption onto $\{110\}$ faces, in particular at the edges of steps parallel to [001]. Such a mechanism is in agreement with electron microscopy observations of epsomite crystals grown in the presence of additives. Additive adsorption at other growth sites such as kinks does not seem to occur here. Adsorption at kinks leads to a plateau in the effectiveness of the inhibitor vs concentration. ${ }^{40}$ This is not observed in the case of epsomite, where a continuous increase in G.I. values with increasing additive concentration is observed, even at values as high as $0.1 \mathrm{M}$. Adsorption on terraces is not ruled out in the case of the large polyacrylate molecules.

3.5. Molecular Modeling of Epsomite Morphology and Additive-Epsomite Interactions. The structure (fractional atomic coordinates and site occupancy parameters) used to model the unit cell of epsomite (Figure 7) was solved by Baur ${ }^{68}$ and subsequently refined by Ferraris et al. ${ }^{69}$ and Calleri et al. ${ }^{53}$ Figure 8 shows the observed and calculated morphologies of epsomite crystals. Although none of the calculated morphologies could fully reproduce the observed morphologies of additive- 


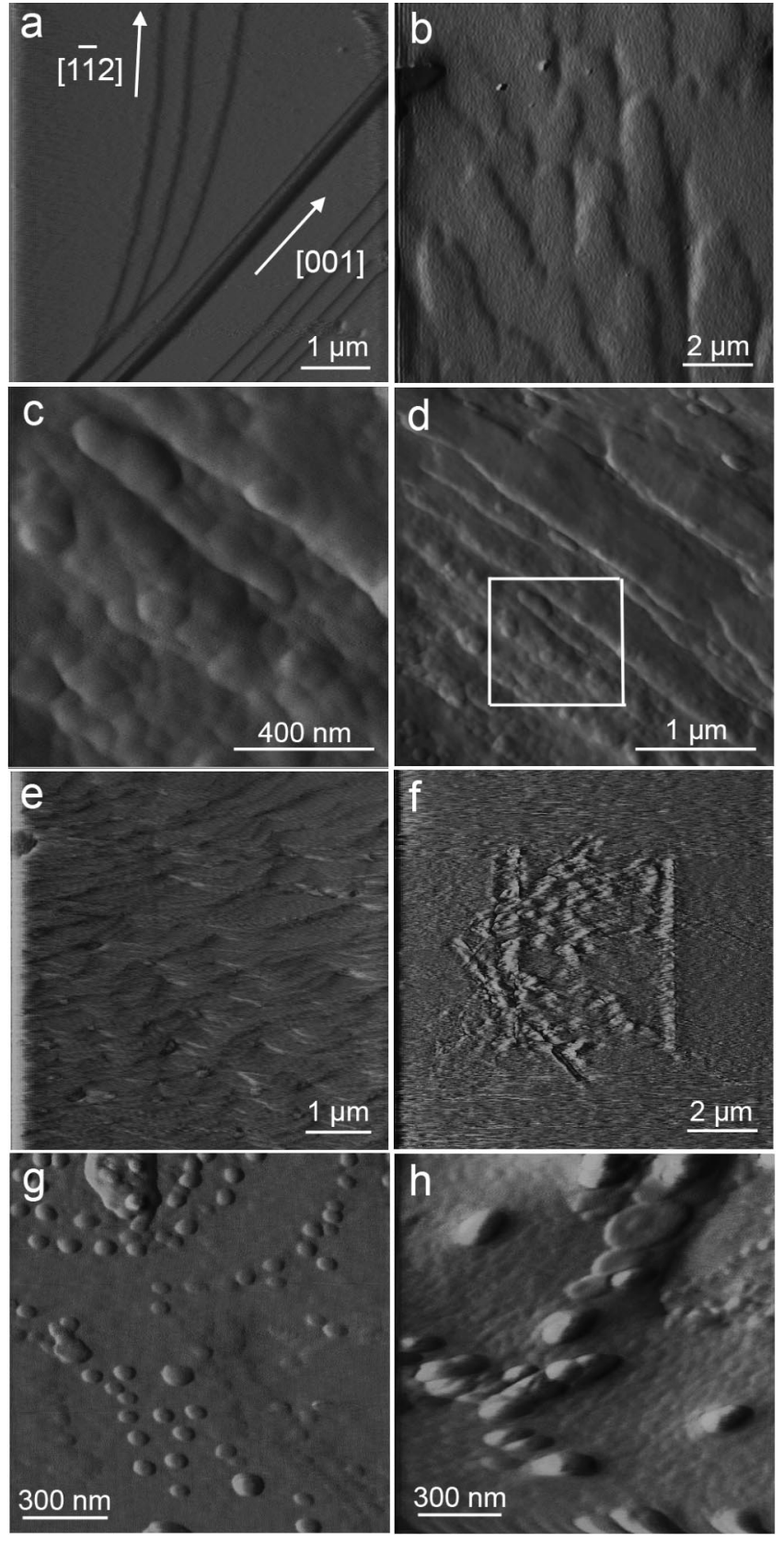

Figure 6. AFM images of the epsomite (110) surface showing: (a) growth steps parallel to [001] and [11 2] in an additive-free crystal; (b) scalloped steps developed in the presence of 0.01 M DTPMP; (c) secondary nuclei formed in the presence of $0.01 \mathrm{M} \mathrm{PA}$; (d) overall view of the area (square) depicted in (c) showing steps developed along [001]; (e) scalloped steps (roughly oriented along [001]) developed in the presence of $0.01 \mathrm{M}$ ATMP; (f) soft layer of (additive) material formed on crystals developed in the presence of 0.01 M HEDP; 2D nuclei on epsomite crystals formed in the presence of 0.01 M AAS (g) and $0.01 \mathrm{M} \mathrm{CA}(\mathrm{h})$.

free epsomite crystals, predicted BFDH and AE growth morphologies are in good agreement with both the prismatic morphology observed by ESEM (control runs), and the morphology described by other authors. ${ }^{53,70}$ Both the observed and the calculated morphologies indicate that the growth of $\{110\}$ faces is the slowest, and, as a consequence, they are morphologically more important. The $\{110\}$ faces account for the biggest proportion of the crystal surface $(64 \% \rightarrow \mathrm{BFDH}$ and $37 \% \rightarrow$ AE growth morphology). However, when the SE equilibrium morphology method was used, $\{020\}$ becomes the
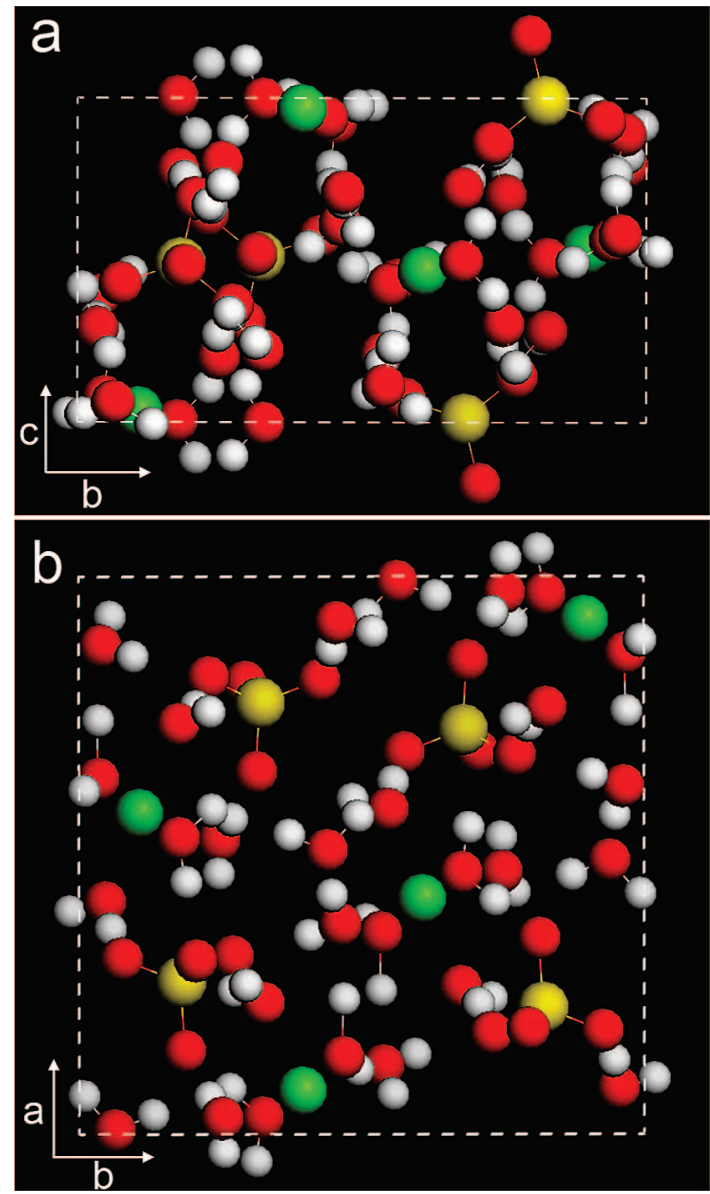

Figure 7. The structure of epsomite projected along (a) [100] and (b) [001] directions. Legend: (red) O; (white) H; (green) Mg; (yellow) S.

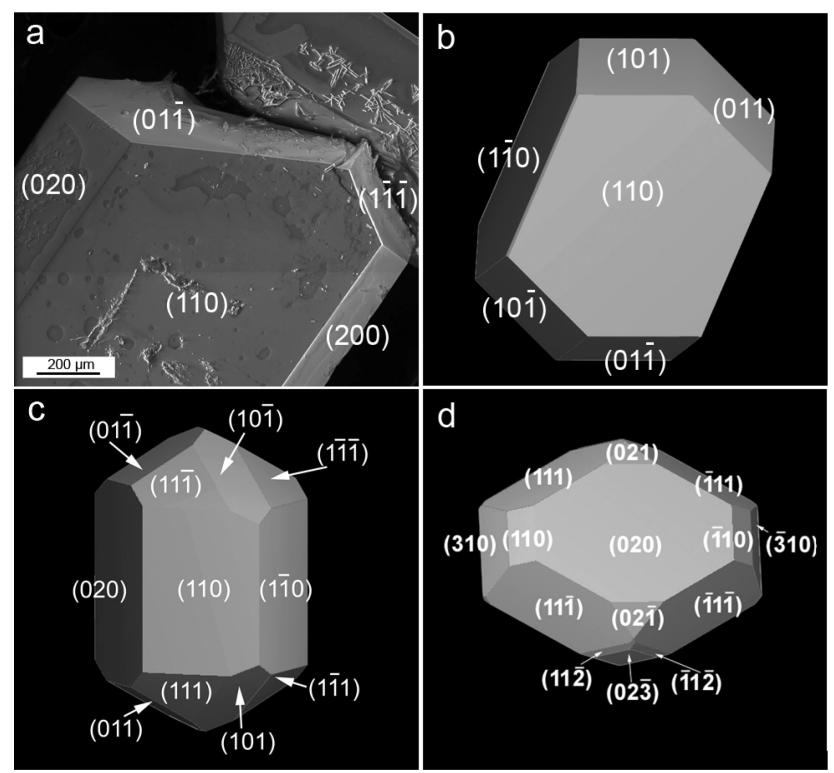

Figure 8. Morphology of epsomite crystals: (a) observed using ESEM, and predicted using (b) the BFDH, (c) AE, and (d) SE algorithms.

most developed form (26\% vs $4 \%$ of $\{110\}$ faces). Yet, the latter face was either not present (Figure 3a,b) or displayed little development (Figure 8a) in additive-free epsomite crystals. The lack of agreement between the observed epsomite form and that 

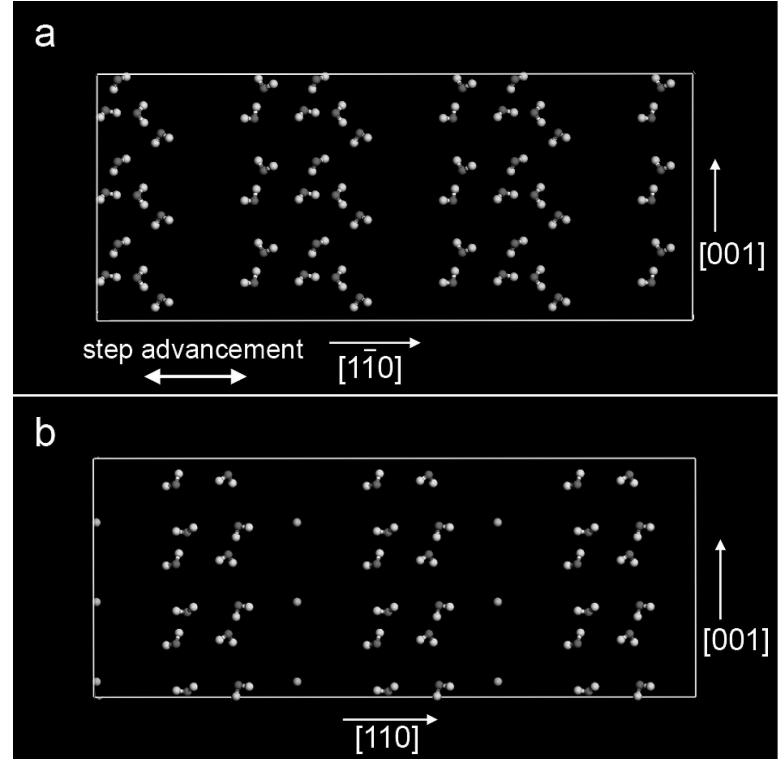

Figure 9. Water molecules in epsomite (a) (110) and (b) (110) cleavage planes (six unit cells are presented; legend as is Figure 7).

predicted using the SE method could be due to the limitations of this method in the case of noncentrosymmetric crystals (see section 2.3).

When reducing the growth rate of the slowest growing (110) face (and symmetry equivalent faces) in the $\langle 110\rangle$ directions, the $\{110\}$ form will still be the morphologically more important. However, a change in habit from prismatic to acicular will take place. This habit change was observed when ATMP, DTPMP, and PA were present and indicates that interaction between these additives and epsomite crystals may take place through adsorption of the additives on this face. AFM observations have also shown that these additives exert their influence by inhibiting the growth of the $\{110\}$ faces along $\langle 110\rangle$ directions through adsorption at steps parallel to the [001] direction. [001] is a direction of high water molecule lineal density in the $\{110\}$ planes (Figure 9). Hydrogen bonding between additive functional groups and epsomite water molecules in such a direction will prevent step movement in the direction perpendicular to [001], that is, along $\langle 110\rangle$, as observed with the AFM. The establishment of hydrogen bonds is consistent with the FTIR results. Other $(h k l)$ planes with a high density of water molecules are the $\{010\}$ planes, although much lower than in the case of the $\{110\}$ planes. Thus, limited hydrogen bonding between additives (DTPMP and PA) and water molecules may also occur, leading to the observed overdevelopment of the $\{020\}$ form. However, establishment of hydrogen bonding does not fully explain why DTPMP is by far the most effective nucleation inhibitor tested. It should be noted that besides the establishment of hydrogen bonding, a molecular modeling of the docking of DTPMP $^{8-}$ ions (the most abundant species at $\left.\mathrm{pH} 8\right)^{29}$ onto epsomite (110) slices shows a perfect stereochemical matching between two $\mathrm{Mg}$ atoms per unit cell and the additive molecule (Figure 10). The molecular modeling suggests that both electrostatic effects and hydrogen bonding contribute to the superior capacity of DTPMP as an effective crystallization inhibitor of epsomite.

\section{Conclusions}

Considering the different additives tested, several act as inhibitors of epsomite crystallization and growth. Small mol-

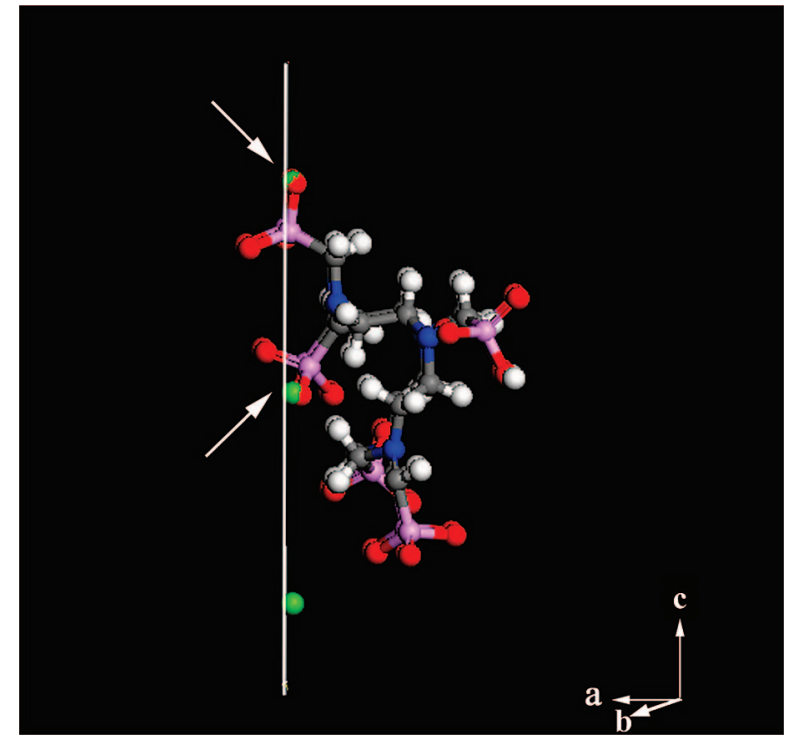

Figure 10. Example of possible docked position of DTPMP ${ }^{8-}$ molecules on epsomite (110) (lateral view of the epsomite (110) surface). For clarity, only $\mathrm{Mg}$ cations of epsomite are shown. Legend: purple $=\mathrm{P}$; red $=\mathrm{O}$; blue $=\mathrm{N}$; light gray $=\mathrm{H}$; dark gray $=\mathrm{C}$; green $=\mathrm{Mg}$.

ecules with low charge such as AAS do not have any significant effect, whereas small molecules with several functional groups (ATMP and DTPMP) and macromolecules (PA) adsorb on the dominant $\{110\}$ face. The overdevelopment of the epsomite $\{110\}$ form observed when DTPMP, ATMP, and PA were added to magnesium sulfate solutions confirms the possibility of additive adsorption on this face. Limited adsorption of DTPMP and PA on $\{010\}$, resulting in the development of epsomite crystals with tabular morphology, also takes place. The AFM analysis suggests that attachment of additive molecules at step edges parallel to [001] occurs. Such a direction is characterized by a high lineal density of water molecules. Thus, AFM results point to hydrogen bonding between the organic molecules and epsomite water molecules on $\{110\}$ as the main mechanism of additive-crystal interaction. The FTIR analysis of additive-doped epsomite crystals confirms the presence of such additives in the crystal lattice and indicates the existence of hydrogen bonding between the additives and structural water in epsomite. Although HEDP is a small molecule with only two phosphonates groups, the presence in its backbone of a hydroxyl group makes it display a high nucleation inhibition capability, similar to that of CA or ATMP. However, HEDP and CA, do not appear to be effective habit modifiers, most probably because they are not very effective at limiting step propagation along the $\langle 110\rangle$ direction. DTPMP is the most effective nucleation inhibitor and habit modifier tested, because in addition to its ability to establish hydrogen bonds with epsomite water molecules, it also shows a high stereochemical affinity with $\mathrm{Mg}$ atoms in $\{110\}$ surfaces as shown by molecular modeling. In general, phosphonates seem to be the most effective additives for the control of epsomite crystallization. The mechanism of additive-epsomite crystal interaction seems to be ruled by certain factors such as the size and charge of the additive molecule and the structural fit between the organic molecule and a particular crystal face. However, the high number of water molecules on epsomite $\{110\}$ faces in comparison with other faces of the crystal makes the interaction, primarily electrostatic, not highly selective. Such a 
high number of water molecules leads to a number of different possibilities of matching between additive molecule and crystal surface, and thus the requirement of structural matching is fulfilled by different additives.

The tested additives, DTPMP in particular, could be used for preventing salt damage associated with the crystallization of epsomite in ornamental stone. Nonetheless, from a conservation-oriented point of view, additional crystallization tests in stone and, subsequently, in pilot areas of buildings affected by salt problems, are needed to confirm this hypothesis.

Acknowledgment. This research was financed by the European Commission VIth Framework Program (contract no. SSP1CT-2003-501571), by the Spanish Government (contract no. MAT2006-00578), and by research group RNM-179 (Junta de Andalucía, Spain). We thank CEAMA (Junta de AndalucíaUniversidad de Granada) for their assistance with ESEM analysis.

\section{References}

(1) Fortes, A. D. Axis 2005, 1, 1-28.

(2) Hardie, L. A. Am. J. Sci. 1984, 284, 193-240.

(3) Goudie, A. S.; Cooke, R. U. Geoforum 1984, 15, 563-582.

(4) Ruiz-Agudo, E.; Martín-Ramos, D.; Rodriguez-Navarro, C. J. Phys. Chem B 2007, 111, 41-52.

(5) Ramalingom, S.; Podder, J.; Kalkura, N.; Bocelli, G. J. Cryst. Growth 2003, 247, 523-529.

(6) Lewis, J. S. Earth Planetary Sci. Lett. 1967, 2, 29-32.

(7) Kargel, J. S. Icarus 1991, 94, 368-390.

(8) Chou, I. M.; Seal, R. Astrobiology 2003, 3, 619-630.

(9) Vaniman, D. T.; Bish, D. L.; Chipera, S. J.; Foalops, C. L.; Carey, J. W.; Feldman, W. C. Nature 2004, 431, 663-665.

(10) Chipera, S. J.; Vaniman, D. T. Geochim. Cosmochim. Acta 2007, 71, 241-250.

(11) McCord, T. B.; Hansen, G. B.; Fanale, F. P.; Carlson, R. W.; Matson, D. L.; Johnson, T. V.; Smythe, W. D.; Crowley, J. K.; Martin, P. D.; Ocampo, A.; Hibbitts, C. A.; Granahan, J. C. Science 1998, 280, 12421245.

(12) McCord, T. B.; Hansen, G. B.; Hibbitts, C. A. Science 2001, 292, $1523-1525$

(13) Gaidos, E. J.; Nealson, K. H.; Kirschvink, J. L. Science 1999, 284, $1631-1633$

(14) Dalton, J. B.; Prieto-Ballesteros, O.; Kargel, J. S.; Jameison, C. S.; Juliet, J.; Quinn, R. Icarus 2005, 173, 472-490.

(15) Montgomery, D. R.; Gillespie, A. Geology 2005, 33, 625-628.

(16) Peterson, R. C.; Wang, R. Y. Geology 2006, 34, 957-960.

(17) La Iglesia, A.; Garcia del Cura, M. A.; Ordoñez, S. Sci. Total Environ. 1994, 152, 179-188.

(18) Matsouka, N. Geomorphology 1995, 12, 323-339.

(19) Goudie, A. S.; Viles, H. Salt Weathering Hazards; Wiley, Chichester, 1997.

(20) ASTM C 88-90, Standard test method for soundness of aggregate by use of sodium sulfate or magnesium sulfate, In Ann. Book ASTM Stand.; ASTM: West Conshohocken, PA, 1997; Vol. 4, Chapter 2, pp $37-42$.

(21) Winkler, E. M.; Singer, P. C. Geol. Soc. Am. Bull. 1972, 83 (11), 3509-13.

(22) La Iglesia, A.; González, V.; López-Acevedo, V.; Viedma, C. J. Cryst. Growth 1997, 177, 111-118.

(23) Chabas, A.; Jeannette, D.; Lefèvre, R. A. Atmos. Environ. 2000, 34, 219-224.

(24) Pye, K.; Schiavon, N. Nature 1989, 342, 663-664.

(25) Cobourn, W. G.; Gauri, K. L.; Tambe, S.; Li, S. H.; Saltik, E. Atmos. Environ. 1993, 27, 193-201.

(26) Laue, S.; Siedel, H.; Pfefferkorn, S. In Kwiatkowki, D., Löfvendahl, R., Eds. Proceedings of the 10th International Congress on Deterioration and Conservation of Stone; Stockholm: ICOMOS, 2004.

(27) Fort, R.; Varas, M. J.; Perez-Montserrat, E.; Vazquez-Calvo, C. Macla 2005, 3, 77-79.

(28) Lazzarini, L.; Tabasso, M. Il Restauro della Pietra. CEDAM: Padova 1986 ,

(29) Ruiz-Agudo, E.; Rodriguez-Navarro, C.; Sebastian-Pardo, E. Cryst. Growth Des. 2006, 6, 1575-1583.
(30) Rodriguez-Navarro, C.; Doehne, E.; Sebastian, E. Langmuir 2000, 16 , 947-954.

(31) Selwitz, C.; Doehne, E. J. Cultural Heritage 2002, 3, 205-216.

(32) Rodriguez-Navarro, C.; Fernández, L. L.; Doehne, E.; Sebastian, E. J. Cryst. Growth 2002, 243, 503-516.

(33) Lubelli, B.; van Hees, R. P. J.; Inc., H. P.; Groot, C. J. W. P. Cem. Concr. Res. 2006, 36, 678-687.

(34) Black, S. N.; Bromley, L. A.; Cottier, D.; Davey, R. J.; Dobbs, B.; Rout, J. E. J. Chem. Soc., Faraday Trans 1991, 87, 3409-3414.

(35) van der Leeden, M. C.; van Rosmalen, G. M. J. Colloid Interface Sci. 1995, 171, 142-149.

(36) Rohl, A. L.; Gay, D. H.; Davey, R. J.; Catlow, C. R. A. J. Am. Chem. Soc. 1996, 118, 642-648.

(37) Bosbach, D.; Hall, C.; Putnis, A. Chem. Geol. 1998, 151, 143-160.

(38) Bosbach, D.; Coveney, P. V.; Griffin, J. L. W.; Putnis, A.; Risthaus, P.; Stackhouse, S.; Whiting, A. J. Chem. Soc., Perkin Trans. 2002, 2 , $1238-1245$

(39) Jones, F.; Oliveira, A.; Rohl, A. L.; Parkinson, G. M.; Ogden, M. I.; Reyhani, M. M. J. Cryst. Growth 2002, 237-239, 424-429.

(40) Pina, C. M.; Putnis, C. V.; Becker, U.; Biswas, S.; Carroll, E. C.; Bosbach, D.; Putnis, A. Surf. Sci. 2004, 553, 61-74.

(41) Jonasson, R. G.; Rispler, K.; Wiwchar, B.; Gunter, W. D. Chem. Geol. 1996, 132, 215-225.

(42) He, S.; Kan, A. T.; Tomson, M. B. Appl. Geochem. 1999, 14, 17-25.

(43) Guo, J.; Severtson, S. J. Ind. Eng. Chem. Res. 2004, 43 (17), 54115417.

(44) Kan, A. T.; Fu, G.; Tomson, M. B. J. Colloid Interface Sci. 2005, 281 (2), 275-284.

(45) Harmandas, N. G.; Navarro Fernandez, E.; Koutsoukos, P. G. Langmuir 1998, 14, 1250-1255.

(46) Cody, A. M.; Cody, R. D. J. Cryst. Growth 1994, 135, 235-245.

(47) Qui, S. R.; Wierzbicki, A.; Orme, C. A.; Cody, A. M.; Hoyer, J. R.; Nancollas, G. H.; Zepeda, S.; De Yoreo, J. J. Proc. Natl. Acad. Sci. U. S. A. 2004, 101, 1811-1815.

(48) Zieba, A.; Sethuraman, G.; Pérez, F.; Nancollas, G. H.; Cameron, D. Langmuir 1996, 12, 2853-2858.

(49) Jiang, H. D.; Liu, X. Y.; Zhang, L. Y. J. Biol. Chem. 2005, 280, 4206142066.

(50) König, A.; Emons, H. H. Cryst. Res. Technol. 1988, 23, 319-326.

(51) Drela, I.; Falewicz, P.; Kuczkowska, S. Water Res. 1998, 32, 31883191.

(52) Rodriguez-Navarro, C.; Doehne, E. Am. Lab. 1999, 31, 28-35.

(53) Calleri, M.; Gavetti, A.; Ivaldi, G.; Rubbo, M. Acta Crystallogr. B 1984, 40, 218-222.

(54) Sikirić, M.; Babić-Ivančić, V.; Milat, O.; Sarig, S.; Füredi-Milhofer, H. Langmuir 2000, 16, 9261-9266.

(55) Agarwal, P.; Berglund, K. A. Cryst. Growth Des. 2004, 4, 479-483.

(56) Nowack, B. Water Res. 2003, 37, 2533-2546.

(57) Dawson, R. M. C.; Elliot, D. C.; Jones, K. M.; Elliot, W. H. Data for Biochemical Research; Oxford University Press: Oxford, 1989.

(58) Chen, K. M.; Jiang, X.; Kimerling, L. C.; Hammond, P. T. Langmuir 2000, 16, 7825-7834.

(59) Hogenboom, D. L.; Kargel, J. S.; Ganasan, J. S.; Lee, L. Icarus 1995, $115,258-277$.

(60) Mullin, J. W. Crystallization; Butterworth-Heinemann: Oxford, 1993.

(61) Myneni, S. C. B. X-ray and vibrational spectroscopy of sulfate in earth materials. In Sulfate Minerals; Alpers, C. N.; Jambor, J. L.; Nordstrom, D. K., Eds.; Reviews in Mineralogy and Geochemistry, Vol. 40; Mineralogical Society of America: Washington, DC, 2000.

(62) Colthup, N. B.; Daly, L. H.; Wiberley, S. E., Introduction to Infrared and Raman Spectroscopy, 3rd ed.; Academic Press: New York, 1990.

(63) Chaban, G. M.; Huo, W. M.; Lee, T. J. J. Chem. Phys. 2002, 117, 2532-2537.

(64) Coates, J. In Encyclopedia of Analytical Chemistry; Meyers, R. A. Ed.; John Wiley \& Sons: Chichester, UK, 2000; pp 10815-10837.

(65) Pina, C. M.; Becker, U.; Rishaus, P.; Bosbach, D.; Putnis, A. Nature 1998, 395, 483-486.

(66) Lacmann, R.; Herden, A.; Mayer, C. Chem. Eng. Technol. 1999, 22, 279-289.

(67) Freij, S. J.; Parkinson, G. M. Hydrometallurgy 2005, 78, 246-255.

(68) Baur, W. H. Acta Crystallogr. 1964, 17, 1361-1369.

(69) Ferraris, G.; Jones, D. W.; Yerkess, J. J. Chem. Soc., Dalton Trans. 1973, 816-821.

(70) Sgualdino, G.; Vaccari, G.; Aquilano, D.; Rubbo, M. J. Cryst. Growth 1987, 83, 523-527.

CG070442N 